\title{
Complete mitogenome of the Lesser Purple Emperor Apatura ilia (Lepidoptera: Nymphalidae: Apaturinae) and comparison with other nymphalid butterflies
}

\author{
CHEN Mei ${ }^{1}$, TIAN Li-Li ${ }^{1}$, SHI Qing-Hui ${ }^{1}$, CAO Tian-Wen ${ }^{2, *}$, HAO Jia-Sheng ${ }^{1, *}$ \\ (1. College of life Sciences, Anhui Normal University, Wuhu Anhui 241000, China; 2. Institute of Plant Protection, \\ Shanxi Academy of Agriculture Science, Taiyuan Shanxi 030031, China)
}

\begin{abstract}
The complete mitochondrial genome of Apatura ilia (GenBank accession no. JF437925) was determined as a circular DNA molecule of $15242 \mathrm{bp}$, with common genes of 13 putative proteins, 2 rRNAs, and 22 tRNAs and of the same gene arrangement as in other sequenced lepidopterans. All protein-coding genes had the typical start codon ATN, except for the COI's using CGA as its start codon as previously demonstrated in other lepidopteran species. The comparison of the nucleotide sequences of the A. ilia mitogenome with ten other Nymphalidae species showed nearly identical gene orientation and arrangement, with only a few alterations in non-coding fragments. The nucleotide composition and codon frequency all fell into the range estimated for the order Lepidoptera. The $A$. ilia mitochondrial genome had the canonical set of 22 tRNA genes folded in the typical cloverleaf structure, with an unique exception of tRNA $^{\text {Ser }}(\mathrm{AGN})$. The mitochondrial genes from $A$. ilia were overlapped in a total of $33 \mathrm{bp}$ at 9 locations, as well as interleaved with a total of $155 \mathrm{bp}$ intergenic spacers, spread over 12 regions with the size ranging from 1 to $49 \mathrm{bp}$. Furthermore, the spacer between ND6 and Cyt $b$ harbored a microsatellite-like repeat (TA $)_{23}$ not found in other completely sequenced nymphalid genomes. The $403 \mathrm{bp}$ AT-rich region harbored two conserved motifs (ATAGA, ATTTA), a 21 bp polyT stretch, a 10 bp poly-A region, along with two microsatellite-like repeats ( (TA $)_{10}$ and (TA $)_{7}$ ), as detected in other nymphalid butterflies.
\end{abstract}

Key words: Mitochondrial genome; Lepidoptera; Nymphalidae; Apatura ilia

\section{柳紫闪蛱蝶线粒体基因组全序列及与相关蛱蝶类的比较分析}

\author{
陈 梅 ${ }^{1}$, 田丽丽 ${ }^{1}$, 石庆会 ${ }^{1}$, 曹天文 ${ }^{2,{ }^{*}}$, 郝家胜 ${ }^{1, *}$ \\ （1. 安徽师范大学生命科学学院分子进化与生物多样性研究室, 安徽 芜湖 241000; \\ 2. 山西省农业科学院 植物保护研究所昆虫研究室, 山西太原 030031)
}

摘要: 该文对柳紫闪蛱蝶 Apatura ilia(鳞翅目: 蛱蝶科)的线粒体基因组全序列进行了测定, 同时结合其它已 知蛱蝶类的相应序列进行了比较分析。结果显示: 柳紫闪蛱蝶的线粒体基因组(GenBank accession no.: JF437925) 是一个 $15242 \mathrm{bp}$ 的环状 DNA 分子, 包含 13 个蛋白质编码基因、 2 个 rRNA 基因 和 22 个 tRNA 基因。13 个蛋白 编码基因中, 除了 COI 基因的起始密码子是 CGA 外, 其余 12 个蛋白编码基因都具有标准的 ATN 起始密码子; 柳 紫闪蛱蝶与其它已测的 10 种蛱蝶在基因定位和排列顺序方面几乎相同, 只是在非编码序列上存在细微的差异, 其

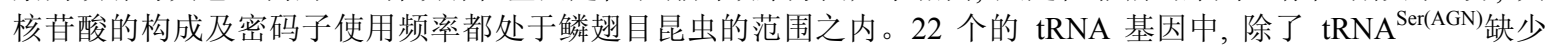
DHU 臂, 其余的 tRNA 基因都显示为典型的三叶草结构。基因组共存在 9 处基因间重叠区(总长度为 $33 \mathrm{bp}$ )以及 12 个基因间隔区(总长为 $155 \mathrm{bp}$, 最长间隔是 $49 \mathrm{bp}$, 最短的是 $1 \mathrm{bp}$ )。在 ND6 和 Cyt b 间的间隔区中还发现有(TA) 23 似 微卫星结构。与其他蛱蝶类相似, $403 \mathrm{bp}$ 的 AT 富集区包含有 ATAGA, ATTTA二个保守模块(一个 21 bp 的 poly-T, 一个 $10 \mathrm{bp}$ 的 poly-A), 以及二个似微卫星的重复结构 $\left((\mathrm{TA})_{10} \text { 和 }(\mathrm{TA})_{7}\right)_{\text {。 }}$

关键词: 线粒体基因组; 鳞翅目; 蛱蝶科; 柳紫闪蛱蝶

Received date: 2011-10-24; Accepted date: $2012-02-20$

Foundation items: This work was supported by grants from the National Science Foundation of China $(41172004,40871034)$ and partially by the Provincial Key Projects of Natural Science Foundation, Colleges of Anhui Province (KJ2010A142)

*Corresponding author (通信作者), E-mail: ctwen@126.com; jshaonigpas@sina.com

收稿日期: 2011-10-24; 接受日期: 2012-02-20 
中图分类号：Q969.42; Q969.439.2; Q754 文献标志码：A＼cjkstart文章编号：0254-5853-(2012)02-0191-11

Present butterfly taxonomy classifies the Lesser Purple Emperor Apatura ilia into the subfamily Apaturinae (Lepidoptera: Nymphalidae) (Chou, 1998). This butterfly species was widely distributed in the Palaearctic Europe and Asia. It's name comes from the butterfly's bright violet reflection under sunshine. In its lifecycle, larvae feed on the leaves of trees including trembling poplar, poplar, aspen and willow, whereas the adults mainly feed on tree sap and animal dejecta (Chou, 2000). Due to habitat destruction and environmental degradation, A. ilia has been designated as endangered or under priority protection in some countries or regions, including Belgium(Li \& Fu, 2000).

The mitochondrial genome of insects is a circular and double-stranded molecule of approximately 14-20 kb in size with highly conserved exon arrangement covering a set of 37 genes, namely 13 PCGs, 22 tRNA genes, and 2 rRNA (srRNA (12S) and lrRNA (16S)) genes (Boore, 1999; Taanman, 1999). A mitogenome features smaller sizes, faster evolutionary rates, higher conservative gene content, maternal inheritance and little recombination (Brown, 1983; Avise, 1994), compared to the nucleic genome. Thus it has been commonly used for taxonomic and phylogenetic studies in many animal groups. The availability of complete mitogenome data of more species remarkably increases the accuracy and efficiency of a variety of research areas, such as molecular phylogenetics, phylogeography and taxonomy.

The complete mitochondrial genomes of nearly 240 insect species are available, of which only 10 are of Papilionoidae, despite its high biodiversity of 17500 species (Robbins, 1982). The Nymphalidae is the largest butterfly family, and relationships with other butterfly groups remain unclear. It is necessary to integrate mitogenome data in the reconstruction of Nymphalidae phylogenies. In this study we sequenced the entire mitogenome of the nymphalid $A$. ilia, a representative butterfly species of the subfamily Apaturinae and compared its nucleotide organization to those of other representative nymphalid butterfly species. Our aim is to provide important molecular data to clarify the phylogenetic relationship between $A$. ilia and other nymphalid butterflies.

\section{Materials and Methods}

\subsection{Sample collection and DNA extraction}

Adult individuals of $A$. ilia were collected from
Mount Yandangshan, Zhejiang, China in August 2008. Samples were quickly preserved in $100 \%$ ethanol and at $20{ }^{\circ} \mathrm{C}$ until DNA extraction. Total genomic DNA was isolated from a single frozen butterfly using the proteinase- $\mathrm{K}-\mathrm{SiO}_{2}$ as follows (Hao et al, 2005). The thorax muscle around $5 \mathrm{~mm}^{3}$ was removed into a $10 \mathrm{~mL}$ Eppendorf tube, washed twice with $\mathrm{ddH}_{2} \mathrm{O}$, and soaked for $2 \sim 3 \mathrm{~h}$. Incubation was done with $500 \mu \mathrm{L}$ DNA solution ( $5 \mathrm{mmol} / \mathrm{L} \mathrm{NaCl}, 0.5 \% \mathrm{SDS}, 15 \mathrm{mmol} / \mathrm{L}$ EDTA, $10 \mathrm{mmol} / \mathrm{L}$ Tris-HCl, $\mathrm{pH}$ 7.6) and $40 \mu \mathrm{L}$ proteinase-K $(20 \mathrm{mg} / \mathrm{mL})$. The muscle was then bathed at $55{ }^{\circ} \mathrm{C}$ for $10 \sim 12 \mathrm{~h}$ and centrifuged at $4000 \mathrm{rpm}$ for $2 \mathrm{~min}$. Liquid supernatant was transferred to a new $10 \mathrm{~mL}$ Eppendorf tube with $500 \mu \mathrm{L} 8 \mathrm{~mol} / \mathrm{L} \mathrm{GuSCN}$ and $40 \mu \mathrm{L} 50 \%$ clean glass liquid mixture, bathed at $37{ }^{\circ} \mathrm{C}$ for $1 \sim 2 \mathrm{~h}$, shocked every ten $\mathrm{min}$ and centrifuged at $4000 \mathrm{rpm}$ for $1 \mathrm{~min}$. The supernatant was removed and sediments were cleaned twice with $75 \%$ alcohol, and once with acetone. The sample was dried thoroughly in a vacuum dryer at $45{ }^{\circ} \mathrm{C}$ prior to the addition of $60 \mu \mathrm{L}$ TE $(10 \mathrm{mmol} / \mathrm{L}$ Tris$\mathrm{Cl}, 1 \mathrm{mmol} / \mathrm{L}$ EDTA, $\mathrm{pH}$ 8.0). The solution was later bathed at $56{ }^{\circ} \mathrm{C}$ for $30 \mathrm{~min}$, and centrifuged at increasing speed untill $4000 \mathrm{rpm}$ for $1 \mathrm{~min}$. The supernatant containing total genomic DNA was removed into a clean $1.5 \mathrm{~mL}$ Eppendorf tube and preserved at $-20^{\circ} \mathrm{C}$ for use.

\subsection{Primer design, PCR amplification and DNA sequencing}

The universal PCR primers for short fragment amplifications of the srRNA, COI and Cyt b genes were synthesized after Simon et al (1994) and Simons \& Weller (2001). Long primers and certain short ones for some genes including COIII and ND5 were designed by the multiple sequence alignments of the complete mitochondrial genomes of all lepidopterans available (Tab. 1), using ClustalX 1.8 (Thompson et al, 1997) and Primer Premier 5.0 (Singh et al, 1998) softwares.

Long PCRs were performed using TaKaRa LA Taq polymerase with the cycling parameters: initial denaturation for $5 \mathrm{~min}$ at $95^{\circ} \mathrm{C}$, followed by 30 cycles of $95{ }^{\circ} \mathrm{C}$ for $50 \mathrm{sec}, 47-61{ }^{\circ} \mathrm{C}$ for $50 \mathrm{sec}, 68^{\circ} \mathrm{C}$ for $2 \mathrm{~min}$ and $30 \mathrm{sec}$; and a final extension step of $68^{\circ} \mathrm{C}$ for $10 \mathrm{~min}$. The short fragments were amplified with TaKaRa Taq polymerase: initial denaturation for $5 \mathrm{~min}$ at $94{ }^{\circ} \mathrm{C}$, followed by 35 cycles of $94{ }^{\circ} \mathrm{C}$ for $1 \mathrm{~min}, 45-53{ }^{\circ} \mathrm{C}$ for 1 $\min , 72{ }^{\circ} \mathrm{C}$ for $2 \mathrm{~min}$; and a final extension step of $72^{\circ}$ 
for $10 \mathrm{~min}$. The PCR products were detected via electrophoresis in $1.2 \%$ agarose gel, purified using the 3S Spin PCR Product Purification Kit and sequenced directly with ABI-3730 automatic DNA sequencer. Mitogenome sequence data have been deposited into GenBank under the accession number JF437925.

\subsection{Sequence analysis}

All genes and the AT-rich region of the A. ilia mitogenome ClustalX 1.8. The nucleotide sequences of protein-coding genes were translated according to the invertebrate mtDNA genetic code. Fifteen of the 22 tRNA genes were identified using the software tRNA Scan-SE 1.21 (Lowe \& Eddy, 1997) and RNAstructure 4.3 (Mathews, 2006). The remaining 7 tRNA genes were drawn manually after comparison with known homologous regions of other lepidopteran insects. MEGA 5.0 software (Tamura et al, 2007) was used to analyze nucleotide composition and codon usage.

\section{Results}

\subsection{Gennome organization}

The complete mitogenome of A. ilia is $15242 \mathrm{bp}$ in size. Similar to most insects, the mitogenome has a set of 37 genes: including 13 protein-coding, 22 tRNA and 2 rRNA genes. A large noncoding $\mathrm{A}+\mathrm{T}$-rich region was identified (Fig. 1). This region is of highly variable

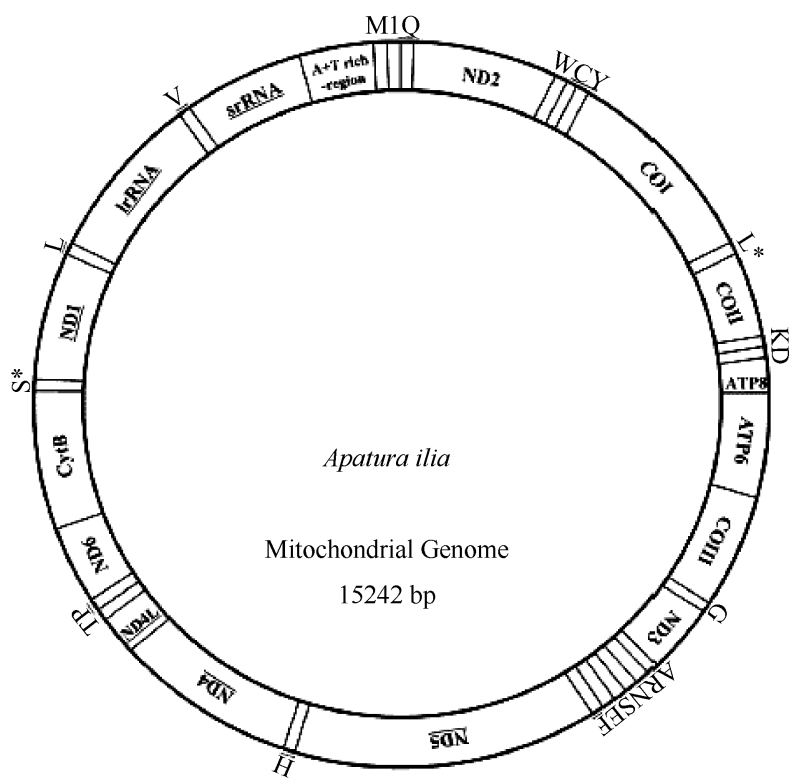

Fig. 1 Circular map of mitogenome of Apatura ilia Abbreviations for genes are as follows: COI-III refers to the cytochrome oxidase subunits, Cyt b refers to cytochrome b, and ND1-6, ND4L refers to NADH dehydrogenase components. tRNAs are denoted as one-letter symbol according to IUPAC-IUB single-letter amino acid codes length in insects and is generally suggested to be the replication and transcription origin sites of the mtDNA double strands (Clayton, 1992). Furthermore the mitogenome of $A$. ilia was found to be highly similar to most sequenced lepidopterans in terms of gene order and orientation. Nine protein-coding genes were found in the major strand and the remaining 4 protein-coding genes in the minor strand along the mitogenome(Tab. 1). Besides those, the mitogenome of $A$. ilia has 9 overlapped sequences and 12 intergenic sequences.

\subsection{Protein-coding genes, transfer RNA genes and ribosomal RNA genes}

Thirteen protein-coding genes for 3711 amino acids were identified in the mitochondrial genome of $A$. ilia (Tab. 2). The longest one is the COI gene with $1533 \mathrm{bp}$ and the shortest one is ATP8 with only $159 \mathrm{bp}$. Twelve protein-coding genes were initiated by conventional start codon ATN, while only the COI gene was tentatively designated to be CGA as the start codon. In A. ilia, nine protein-coding genes ended with TANs ( 7 with TAA, 2 with TAG), while four genes ended with a single $\mathrm{T}$ right ahead of tRNA genes (Tab. 1).

Twenty-two tRNA genes were found in the mitogenome (Fig. 2), all of the cloverleaf secondary structure except for tRNA ${ }^{\text {ser }}$ (AGN) which harbors a simple loop in the DHU arm. Twenty-two tRNA genes ranged from $62 \mathrm{bp}$ for tRNA ${ }^{\mathrm{Arg}}$ and $\mathrm{tRNA}^{\mathrm{Ser}}$ (AGN) to 71 bp for tRNA ${ }^{\text {Lys }}$ in length(Tab. 3).

As in other lepidopteran species, the A. ilia mitogenome was found to harbor two rRNA genes, srRNA (776 bp) and lrRNA (1,333 bp). They are located between $\mathrm{tRNA}^{\mathrm{Leu}}$ (CUA) and an $\mathrm{A}+\mathrm{T}$-rich region, separated by tRNA ${ }^{\mathrm{Val}}$.

\subsection{A+T-rich region, intergenic spacer and overlapping sequences}

The AT-rich region of $A$. ilia was found to be 403 bp in length, located between srRNA and tRNA ${ }^{\text {Met }}$. It had the highest AT content (92.5\%) across the whole mitogenome (Tab. 2), typical in Nymphalidae insects from 89.6\% (Melnitis leda) (Unpublished) to 96.3\% (Libythea celtis) (Unpublished)..In addition, the values of the AT skew and GC skew for this region reached to 0.07 and -0.14 , respectively.

Thirteen intergenic spacer sequences were determined with a total length of $155 \mathrm{bp}$ (Tab. 4). The longest two intergenic spacer sequences were both $49 \mathrm{bp}$ long and located between tRNA ${ }^{\mathrm{Gln}}$ and ND2 and ND6 and Cyt $b$. The shortest one was only $1 \mathrm{bp}$ in size. The 
Tab. 1 Summary of the Apatura ilia mitogenome

\begin{tabular}{|c|c|c|c|c|c|c|}
\hline Gene & Direction & Nucleotide no. & Size & Anticodon & Start codon & Stop codon \\
\hline tRNA ${ }^{\mathrm{Met}}$ & $\mathrm{F}$ & $1-68$ & 68 & CAT32-34 & & \\
\hline tRNA $^{\text {Ile }}$ & F & $69-133$ & 65 & GAT98-100 & & \\
\hline $\mathrm{tRNA}^{\mathrm{Gln}}$ & $\mathrm{R}$ & 131-199 & 69 & TTG235-237 & & \\
\hline ND2 & $\mathrm{F}$ & $249-1262$ & 1014 & & ATT & TAA \\
\hline $\mathrm{tRNA}^{\mathrm{Trp}}$ & $\mathrm{F}$ & $1261-1328$ & 68 & TCA1292-1294 & & \\
\hline $\mathrm{tRNA}^{\text {Cys }}$ & $\mathrm{R}$ & $1321-1387$ & 67 & GCA1356-1358 & & \\
\hline $\mathrm{tRNA}^{\mathrm{Tyr}}$ & $\mathrm{R}$ & $1388-1452$ & 65 & GTA1419-1421 & & \\
\hline $\mathrm{COI}$ & $\mathrm{F}$ & $1461-2993$ & 1533 & & CGA & TAA \\
\hline tRNA ${ }^{\text {Leu }}(\mathrm{UUR})$ & $\mathrm{F}$ & $2989-3055$ & 67 & TAA3019-3021 & & \\
\hline COII & $\mathrm{F}$ & $3056-3731$ & 676 & & ATG & T-tRNA \\
\hline $\mathrm{tRNA}^{\mathrm{Lys}}$ & $\mathrm{F}$ & $3732-3802$ & 71 & СТT3762-3764 & & \\
\hline tRNA ${ }^{\text {Asp }}$ & $\mathrm{F}$ & $3803-3869$ & 67 & GTC3834-3836 & & \\
\hline ATPase8 & $\mathrm{F}$ & $3870-4028$ & 159 & & ATT & TAA \\
\hline ATPase6 & $\mathrm{F}$ & $4022-4675$ & 654 & & ATG & TAG \\
\hline COIII & $\mathrm{F}$ & $4684-5475$ & 792 & & ATA & TAA \\
\hline $\mathrm{tRNA}^{\mathrm{Gly}}$ & $\mathrm{F}$ & $5478-5542$ & 65 & TCC5508-5510 & & \\
\hline ND3 & $\mathrm{F}$ & $5540-5894$ & 355 & & ATA & T-tRNA \\
\hline tRNA ${ }^{\text {Ala }}$ & F & $5895-5960$ & 66 & TGC5924-5926 & & \\
\hline tRNA ${ }^{\text {Arg }}$ & $\mathrm{F}$ & $5960-6021$ & 62 & TCG5987-5989 & & \\
\hline tRNA ${ }^{\text {Asn }}$ & $\mathrm{F}$ & $6024-6088$ & 65 & GTT6055-6057 & & \\
\hline $\mathrm{tRNA}^{\mathrm{Ser}}(\mathrm{AGN})$ & F & $6087-6148$ & 62 & GCT6108-6110 & & \\
\hline tRNA ${ }^{\text {Glu }}$ & $\mathrm{F}$ & $6151-6214$ & 64 & TTC6179-6181 & & \\
\hline $\mathrm{tRNA}^{\mathrm{Phe}}$ & $\mathrm{R}$ & $6215-6278$ & 64 & GAA6246-6248 & & \\
\hline ND5 & $\mathrm{R}$ & $6279-8010$ & 1732 & & ATT & T-tRNA \\
\hline $\mathrm{tRNA}^{\mathrm{His}}$ & $\mathrm{R}$ & $8011-8076$ & 66 & GTG8042-8044 & & \\
\hline ND4 & $\mathrm{R}$ & $8077-9415$ & 1339 & & ATG & T-tRNA \\
\hline ND4L & $\mathrm{R}$ & $9417-9701$ & 285 & & ATG & TAG \\
\hline $\mathrm{tRNA}^{\mathrm{Thr}}$ & $\mathrm{F}$ & $9714-9777$ & 64 & TGT9744-9746 & & \\
\hline $\mathrm{tRNA}^{\text {Pro }}$ & $\mathrm{R}$ & $9778-9841$ & 64 & TGG9810-9812 & & \\
\hline ND6 & $\mathrm{F}$ & $9844-10371$ & 528 & & ATA & TAA \\
\hline CytB & $\mathrm{F}$ & 10421-11572 & 1152 & & ATG & TAA \\
\hline $\mathrm{tRNA}^{\mathrm{Ser}}(\mathrm{UCN})$ & $\mathrm{F}$ & 11571-11636 & 66 & GCT11601-11603 & & \\
\hline ND1 & $\mathrm{R}$ & $11650-12591$ & 942 & & ATG & TAA \\
\hline $\operatorname{tRNA}^{\mathrm{Leu}}(\mathrm{CUN})$ & $\mathrm{R}$ & $12599-12666$ & 68 & TAG12635-12637 & & \\
\hline LrRNA & $\mathrm{R}$ & 12667-13999 & 1333 & & & \\
\hline tRNA $A^{\text {Val }}$ & $\mathrm{R}$ & $14000-14063$ & 64 & TAC14032-14034 & & \\
\hline SrRNA & $\mathrm{R}$ & $14064-14839$ & 776 & & & \\
\hline D-loop & & $14840-15242$ & 403 & & & \\
\hline
\end{tabular}

*tRNA abbreviations follow the IUPAC-IUB three-letter code. 

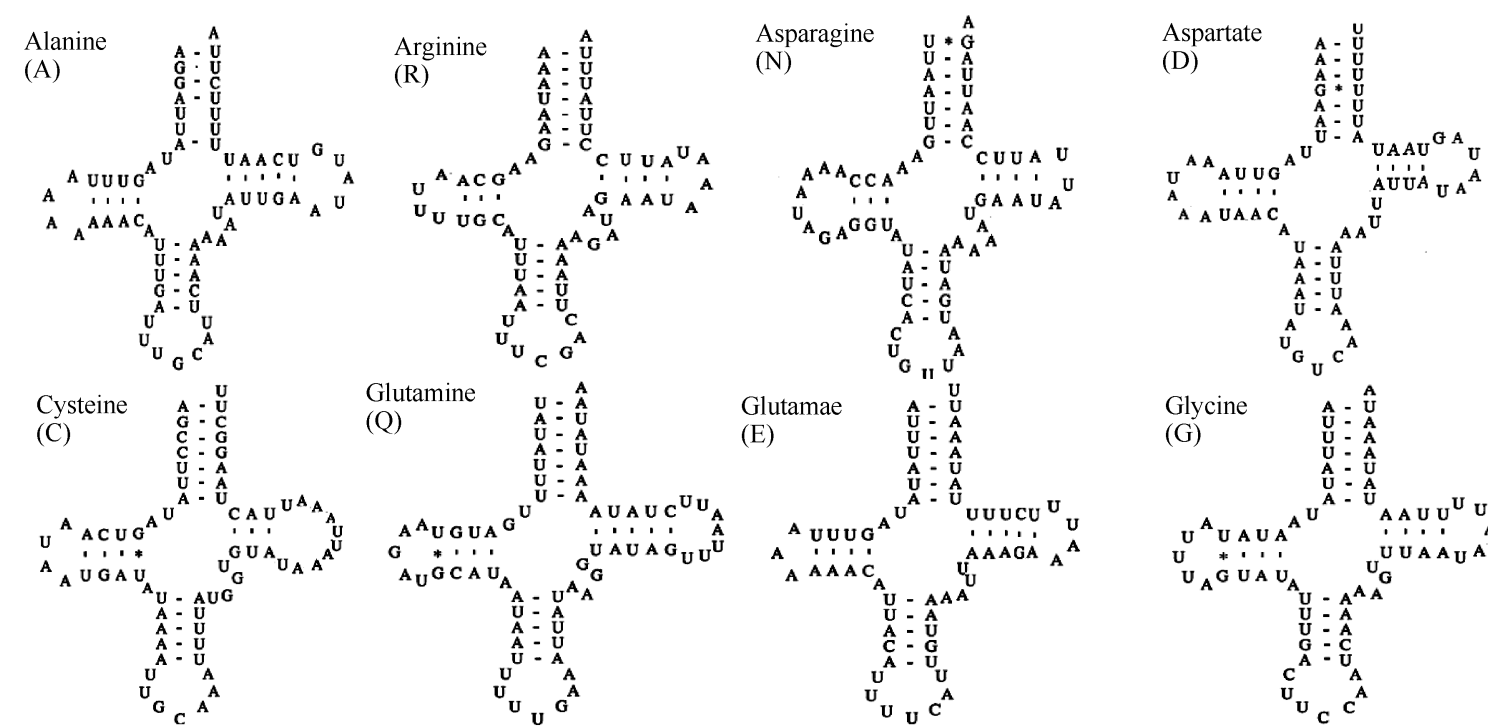

(Q)

(Q)
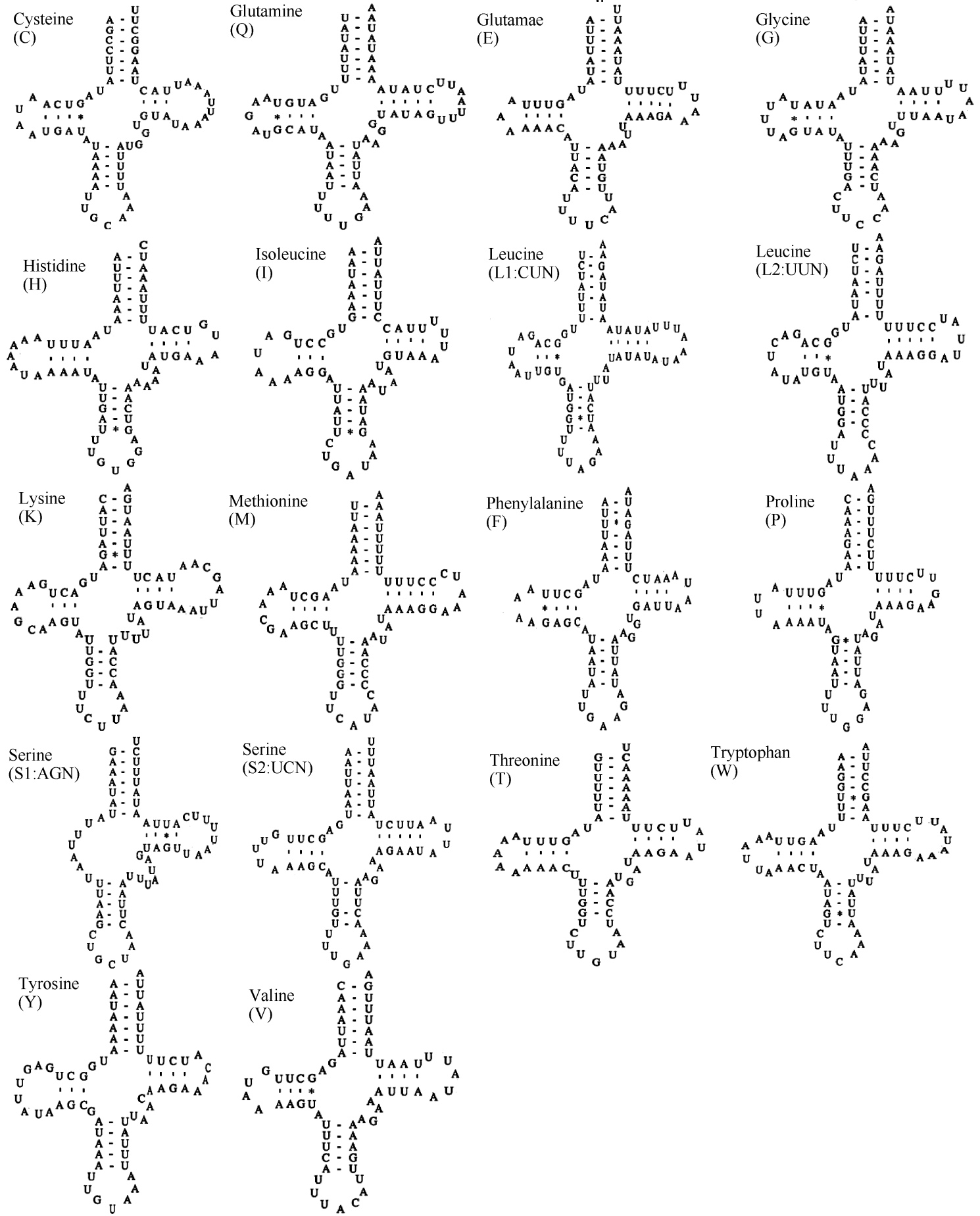

Fig. 2 Predicted secondary cloverleaf structures for the 22 tRNA genes of Apatura ilia

The tRNAs are labeled after amino acid abbreviations. Nucleotide sequences from 5' to 3 ' are indicated for tRNA ${ }^{\text {Ala }}$. Dashes (-) indicated Watson-Crick base-

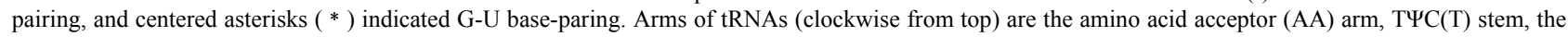
anticodon (AC) arm, and the dihydrouridine (DHU) arm. 
Tab. 2 Comparative characteristics of nymphalid mitogenomes

\begin{tabular}{|c|c|c|c|c|c|c|c|c|c|c|c|c|}
\hline \multirow{2}{*}{ Taxon } & \multirow{2}{*}{$\begin{array}{l}\text { Size } \\
\text { (bp) }\end{array}$} & \multirow{2}{*}{$\begin{array}{l}\text { AT } \\
(\%)\end{array}$} & \multirow{2}{*}{$\begin{array}{c}\text { No. } \\
\text { codons }^{\mathrm{a}}\end{array}$} & \multirow{2}{*}{$\begin{array}{c}\mathrm{PCG}^{\mathrm{b}} \\
\operatorname{AT}(\%)\end{array}$} & \multicolumn{2}{|c|}{ lrRNA } & \multicolumn{2}{|c|}{ srRNA } & \multicolumn{2}{|c|}{ D-loop } & \multirow{2}{*}{$\begin{array}{c}\text { GenBank } \\
\text { Accession No. }\end{array}$} & \multirow{2}{*}{ Reference } \\
\hline & & & & & Size & AT $(\%)$ & Size & $\operatorname{AT}(\%)$ & Size & AT (\%) & & \\
\hline S. charonda & 15244 & 79.9 & 3695 & 78.2 & 1323 & 84.4 & 775 & 85.0 & 380 & 91.8 & NC014224 & GenBank \\
\hline S.kuriyamaensis & 15222 & 79.9 & 3588 & 78.3 & 1311 & 84.2 & 775 & 85.0 & 380 & 91.8 & NC014223 & GenBank \\
\hline C. dauidis & 15267 & 80.4 & 3737 & 78.8 & 1337 & 83.8 & 773 & 85.9 & 403 & 92.5 & HQ658143 & Xia et al, 2011 \\
\hline A. hyperbius & 15156 & 80.8 & 3718 & 79.4 & 1330 & 84.5 & 778 & 85.2 & 349 & 95.4 & JF439070 & Wang et al, 2011 \\
\hline A. ilia & 15242 & 80.5 & 3711 & 78.9 & 1333 & 86.0 & 776 & 84.9 & 403 & 92.5 & JF437925 & This study \\
\hline A. issoria & 15245 & 79.7 & 3728 & 78.0 & 1331 & 83.9 & 788 & 83.7 & 430 & 96.0 & GQ376195 & Hun et al, 2010 \\
\hline H. autonoe & 15489 & 79.1 & 3728 & 76.8 & 1335 & 83.7 & 775 & 85.2 & 678 & 94.6 & GQ868707 & Kim et al, 2010 \\
\hline M. leda & 15122 & 79.8 & 3723 & 79.0 & 1332 & 84.0 & 771 & 85.0 & 317 & 89.6 & JF905446 & Unpublished \\
\hline E. mulciber & 15166 & 81.3 & 3725 & 80.3 & 1314 & 84.6 & 776 & 85.3 & 399 & 93.5 & HQ378507 & Unpublished \\
\hline L. celtis & 15164 & 81.2 & 3722 & 79.9 & 1335 & 84.7 & 775 & 85.4 & 328 & 96.3 & HQ378508 & Unpublished \\
\hline A. metis & 15236 & 80.5 & 3704 & 78.9 & 1333 & 84.5 & 779 & 84.8 & 394 & 92.9 & NC015537 & GenBank \\
\hline
\end{tabular}

${ }^{\mathrm{a}}$ Termination codons were excluded in total codon count; ${ }^{\mathrm{b}}$ Protein-coding genes.

Tab. 3 Sizes of each region of tRNAs in Apatura ilia

\begin{tabular}{|c|c|c|c|c|c|c|c|c|c|c|c|c|c|c|c|c|c|c|c|c|c|c|}
\hline \multirow{2}{*}{ Region } & M & I & Q & W & $\mathrm{C}$ & $\mathrm{Y}$ & $\mathrm{L}^{2}$ & $\mathrm{~K}$ & $\mathrm{D}$ & G & A & $\mathrm{R}$ & $\mathrm{N}$ & $\mathrm{S}$ & $\mathrm{E}$ & $\mathrm{F}$ & $\mathrm{H}$ & $\mathrm{T}$ & $\mathrm{P}$ & $\mathrm{S}^{2}$ & $\mathrm{~L}$ & V \\
\hline & 68 & 65 & 69 & 68 & 67 & 65 & 67 & 71 & 67 & 65 & 66 & 62 & 65 & 62 & 64 & 64 & 66 & 64 & 64 & 66 & 68 & 64 \\
\hline Amino-acylstem & 7 & 7 & 7 & $7^{1}$ & 7 & 7 & $7^{1}$ & $7^{1}$ & $7^{1}$ & 7 & $7^{3}$ & 7 & $7^{1}$ & 7 & 7 & $7^{1}$ & 7 & 7 & 7 & 7 & $7^{1}$ & 7 \\
\hline DHU stem & 4 & 3 & $4^{1}$ & 4 & $4^{1}$ & 3 & $3^{1}$ & 3 & 4 & $4^{1}$ & 4 & 3 & 3 & - & 4 & $4^{2}$ & 4 & 4 & $4^{1}$ & 4 & $3^{1}$ & $4^{1}$ \\
\hline Anticodon stem & 5 & 5 & 5 & $5^{1}$ & 5 & 5 & $5^{1}$ & $5^{1}$ & 5 & 5 & 5 & 5 & 5 & 5 & 5 & 5 & 5 & $5^{1}$ & $5^{1}$ & $5^{2}$ & $5^{1}$ & 5 \\
\hline $\mathrm{T} \Psi \mathrm{C}$ stem & 5 & 4 & 5 & 4 & 3 & 4 & 5 & 4 & 4 & 4 & 5 & 4 & 4 & $4^{1}$ & 5 & 3 & 3 & 4 & 5 & 5 & 5 & 4 \\
\hline DHU loop & 6 & 6 & 5 & 6 & 4 & 8 & 7 & 7 & 6 & 5 & 4 & 4 & 8 & 7 & 3 & 5 & 7 & 5 & 4 & 5 & 6 & 4 \\
\hline Anticodon loop & 7 & 7 & 7 & 7 & 7 & 7 & 7 & 7 & 7 & 7 & 7 & 7 & 7 & 7 & 7 & 7 & 7 & 7 & 7 & 7 & 7 & 7 \\
\hline Variable loop & 4 & 5 & 4 & 4 & 4 & 4 & 4 & 5 & 4 & 4 & 4 & 5 & 5 & 7 & 4 & 4 & 5 & 4 & 4 & 4 & 3 & 4 \\
\hline 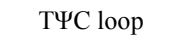 & 5 & 4 & 7 & 7 & 10 & 4 & 5 & 9 & 6 & 5 & 5 & 4 & 3 & 8 & 4 & 6 & 6 & 4 & 3 & 4 & 8 & 5 \\
\hline
\end{tabular}

Transfer RNA genes are labeled by one-letter symbols according to IUPAC-IUB single letter amino acid codes. L, $\mathrm{L}^{2}, \mathrm{~S}$ and $\mathrm{S}^{2}$ indicate tRNA ${ }^{\text {Leu }}(\mathrm{CUN})$, tRNA $^{\text {Leu }}(U U R)$, tRNA $^{\text {Ser }}(A G N)$ and tRNA ${ }^{\text {Ser }}(U C N)$, respectively. Superscripts indicate number of mismatches in each region.

mitogenome of $A$. ilia contains nine overlapping sequences ranging from $1 \mathrm{bp}$ to $8 \mathrm{bp}$ and totaling $33 \mathrm{bp}$ in length.

\section{Discussion}

\subsection{Gene organization and composition}

The length of the complete mitogenome of $A$. ilia falls in the known range of the lepidopteran insects from 15122 bp in M. leda to 16094 bp in Agehana marho (Papilio maraho) (Wu et al, 2010). A. ilia demonstrated a common lepidopteran gene order tRNA ${ }^{\text {Met }}$ followed by tRNA $^{\text {Ile }}$ and by $\mathrm{tRNA}^{\mathrm{Gln}}$, different from those of other insect groups (tRNA ${ }^{\text {Ile }}$ followed by tRNA Gln and by tRNA $^{\text {Met) }}$ (Tab. 1). Gene order was used to explore the presumed independent evolutionary lepidopteran lineages after divergence from their common ancestors (Boore et al, 1998).

The nucleotide composition of the $A$. ilia mitogenome showed considerable bias towards an $\mathrm{A}+\mathrm{T}$ preference (80.5\%) (Tab. 2), a common characteristic observed in insect mitochondrial genomes, ranging from $69.5 \%$ to $84.9 \%$ (Crozier \& Crozier, 1993; Dotson \& Beard, 2001). It was noted that the content of base $\mathrm{T}$ (40.7\%) was slightly higher than base A (39.8\%), resulting in an AT skewness value of -0.012 . The GC composition (19.5\%) was correspondingly lower than AT (Tab. 2) and the GC skewness value was -0.21 .

\subsection{Protein-coding genes}

The putative start codons were found to be the same as in lepidopteran mtDNA (ATN codons: 3 with ATA, 6 with ATG, 3 with ATT) (Tab. 1), except that the COI gene has no uniform start codon (Lessinger et al, 2000; Yukuhiro et al, 2002). In general, lepidopteran insects were quite conservative in using CGA to initiate the COI gene, such as in Eriogyna pyretorum (Jiang et al, 2009), Hyphantria cunea (Liao et al, 2010) and Adoxophyes honmai (Lee et al, 2006). However, there are some 
Tab. 4 Overlapping and intergenic spacer sequences of nymphalid mitogenomes

\begin{tabular}{|c|c|c|c|c|c|c|c|c|c|c|c|}
\hline Region & S.cha & S.kur & C.dau & A.hyp & A.ili & A.iss & H.aut & M.led & A.met & E.mul & L.cel \\
\hline tRNA $^{\text {Met }}$-tRNA ${ }^{\text {Ile }}$ & - & - & - & $(\mathrm{O}) 2$ & - & - & - & - & - & (I) 9 & $(\mathrm{O}) 2$ \\
\hline $\mathrm{tRNA}^{\mathrm{Ile}}-\mathrm{tRNA}^{\mathrm{Gln}}$ & $(\mathrm{O}) 3$ & $(\mathrm{O}) 3$ & $(\mathrm{O}) 3$ & $(\mathrm{O}) 3$ & $(\mathrm{O}) 3$ & $(\mathrm{O}) 3$ & $(\mathrm{O}) 3$ & $(\mathrm{O}) 3$ & $(\mathrm{O}) 3$ & $(\mathrm{O}) 3$ & $(\mathrm{O}) 3$ \\
\hline $\mathrm{tRNA}^{\mathrm{Gln}}-\mathrm{ND} 2$ & (I) 87 & (I) 87 & (I)46 & (I) 52 & (I) 49 & (I) 51 & (I) 50 & (I) 72 & (I) 60 & (I) 46 & (I) 52 \\
\hline ND2-tRNA ${ }^{\text {Trp }}$ & (I) 127 & (O) 15 & $(\mathrm{O}) 2$ & $(\mathrm{O}) 2$ & $(\mathrm{O}) 2$ & (I) 4 & - & $(\mathrm{O}) 2$ & $(\mathrm{O}) 2$ & $(\mathrm{O}) 2$ & (I) 1 \\
\hline $\mathrm{tRNA}^{\text {Trp }}$-tRNA ${ }^{\text {Cys }}$ & $(\mathrm{O}) 8$ & $(\mathrm{O}) 8$ & (O) 8 & $(\mathrm{O}) 8$ & (O) 8 & (O) 8 & (O) 8 & $(\mathrm{O}) 8$ & $(\mathrm{O}) 8$ & $(\mathrm{O}) 8$ & (O) 8 \\
\hline $\mathrm{tRNA}^{\mathrm{Cys}}$-tRNA ${ }^{\mathrm{Tyr}}$ & - & - & - & $(\mathrm{O}) 1$ & - & (I) 1 & - & - & - & (I) 1 & - \\
\hline tRNA ${ }^{\text {Tyr }}$-COI & (O) 19 & (O) 19 & (I) 1 & (I) 3 & (I) 8 & - & (I) 8 & (I) 2 & (I) 5 & (I) 1 & (I) 5 \\
\hline COI-tRNA ${ }^{\text {Leu }}$ & (O) 3 & (O) 5 & - & - & $(\mathrm{O}) 5$ & - & - & - & - & - & - \\
\hline tRNA ${ }^{\text {Leu }}$-COII & - & - & (I) 1 & - & - & - & - & - & - & - & - \\
\hline COII-tRNA ${ }^{\text {Lys }}$ & $(\mathrm{O}) 3$ & $(\mathrm{O}) 3$ & (O)35 & - & - & $(\mathrm{O}) 35$ & - & (O)35 & - & - & - \\
\hline $\mathrm{tRNA}^{\mathrm{Lys}}$-tRNA $\mathrm{Asp}^{\mathrm{Asp}}$ & $(\mathrm{O}) 1$ & $(\mathrm{O}) 1$ & (I) 20 & (O) 1 & - & $(\mathrm{O}) 1$ & (I) 1 & (I) 11 & - & $(\mathrm{O}) 1$ & $(\mathrm{O}) 1$ \\
\hline tRNA $^{\text {Asp }}$-ATP8 & - & - & - & - & - & - & - & - & - & - & - \\
\hline ATP8-ATP6 & $(\mathrm{O}) 7$ & (O)7 & (O)7 & (O) 7 & $(\mathrm{O}) 7$ & $(\mathrm{O}) 7$ & $(\mathrm{O}) 7$ & $(\mathrm{O}) 7$ & $(\mathrm{O}) 7$ & $(\mathrm{O}) 7$ & $(\mathrm{O}) 7$ \\
\hline ATP6-COIII & - & - & $(\mathrm{O}) 1$ & $(\mathrm{O}) 1$ & (I) 8 & $(\mathrm{O}) 1$ & $(\mathrm{O}) 1$ & $(\mathrm{O}) 1$ & $(\mathrm{O}) 1$ & $(\mathrm{O}) 1$ & $(\mathrm{O}) 1$ \\
\hline COIII-tRNA ${ }^{\text {Gly }}$ & (I) 2 & (I) 2 & (I) 2 & (I) 2 & (I) 2 & (I) 2 & (I) 2 & (I) 2 & (I) 2 & (I) 6 & (I) 2 \\
\hline tRNA $^{\text {Gly }}$-ND3 & $(\mathrm{O}) 3$ & $(\mathrm{O}) 3$ & - & - & $(\mathrm{O}) 3$ & - & $(\mathrm{O}) 3$ & - & - & - & - \\
\hline ND3-tRNA ${ }^{\text {Ala }}$ & $(\mathrm{O}) 2$ & (O)2 2 & (I) 22 & (I) 8 & - & (I) 4 & - & - & $(\mathrm{O}) 2$ & $(\mathrm{O}) 2$ & (I) 4 \\
\hline tRNA $^{\text {Ala }}$-tRNA ${ }^{\text {Arg }}$ & (O) 1 & (O) 1 & - & (I) 2 & $(\mathrm{O}) 1$ & (I) 2 & - & (I) 1 & (O) 1 & $(\mathrm{O}) 1$ & - \\
\hline $\mathrm{tRNA}^{\mathrm{Arg}}-\mathrm{tRNA}^{\mathrm{Asn}}$ & - & - & (I) 1 & - & (I) 2 & - & - & (I) 2 & (I) 2 & (I) 1 & (I) 5 \\
\hline $\mathrm{tRNA}^{\mathrm{Asn}}$-tRNA ${ }^{\mathrm{Ser}}$ & (I) 7 & (O) 10 & $(\mathrm{O}) 2$ & $(\mathrm{O}) 2$ & $(\mathrm{O}) 2$ & $(\mathrm{O}) 2$ & $(\mathrm{O}) 3$ & $(\mathrm{O}) 3$ & $(\mathrm{O}) 2$ & $(\mathrm{O}) 2$ & $(\mathrm{O}) 2$ \\
\hline \multicolumn{12}{|l|}{$\mathrm{tRNA}^{\text {Ser- }} \mathrm{tRNA}^{\mathrm{Ser}}$} \\
\hline $\mathrm{tRNA}^{\mathrm{Ser}}{ }_{-\mathrm{tRNA}}^{\mathrm{Glu}}$ & (I) 1 & (I) 1 & (I) 28 & (I) 1 & (I) 2 & (I) 1 & (I) 2 & - & (I) 2 & (I) 8 & (I) 1 \\
\hline $\mathrm{tRNA}^{\mathrm{Glu}}$-tRNA ${ }^{\mathrm{Phe}}$ & $(\mathrm{O}) 2$ & $(\mathrm{O}) 2$ & $(\mathrm{O}) 2$ & (I) 3 & - & $(\mathrm{O}) 2$ & $(\mathrm{O}) 2$ & $(\mathrm{O}) 2$ & - & $(\mathrm{O}) 2$ & $(\mathrm{O}) 2$ \\
\hline tRNA ${ }^{\text {Phe }}$-ND5 & (O)26 & (O)26 & (O) 1 & $(\mathrm{O}) 1$ & - & (O) 1 & - & (O)29 & - & - & - \\
\hline ND5-tRNA ${ }^{\text {His }}$ & (I) 15 & - & - & (I) 15 & - & (I) 8 & $(\mathrm{O}) 3$ & - & (I) 24 & (I) 15 & - \\
\hline tRNA ${ }^{\text {His }}$-ND4 & $(\mathrm{O}) 53$ & (I) 116 & $(\mathrm{O}) 1$ & (O) 1 & - & (I) 4 & - & - & & - & - \\
\hline ND4-ND4L & $(\mathrm{O}) 1$ & (I) 14 & $(\mathrm{O}) 1$ & (I) 2 & (I) 1 & - & $(\mathrm{O}) 1$ & (I) 23 & (I) 1 & $(\mathrm{O}) 1$ & (I) 2 \\
\hline ND4L-tRNA ${ }^{\text {Thr }}$ & (I) 5 & (I) 5 & (I) 5 & (I) 2 & (I) 12 & (I) 2 & (I) 2 & (I) 2 & (I) 12 & (I) 2 & (I) 2 \\
\hline $\mathrm{tRNA}^{\mathrm{Thr}}$-tRNA ${ }^{\text {Pro }}$ & - & - & - & - & - & - & - & - & - & - & - \\
\hline tRNA ${ }^{\text {Pro }}$-ND6 & (I) 51 & (I) 2 & (I) 2 & (I) 4 & (I) 2 & (I) 5 & (I) 2 & (I) 5 & (I) 2 & (I) 2 & (I) 2 \\
\hline ND6-CytB & (I) 6 & (I) 6 & $(\mathrm{O}) 1$ & $(\mathrm{O}) 1$ & (I) 49 & (I) 3 & $(\mathrm{O}) 1$ & $(\mathrm{O}) 1$ & (I) 37 & (I) 4 & $(\mathrm{O}) 1$ \\
\hline CytB-tRNA ${ }^{\text {Ser }}$ & (I) 2 & (I) 355 & - & $(\mathrm{O}) 2$ & $(\mathrm{O}) 2$ & $(\mathrm{O}) 2$ & (I) 8 & (I) 8 & $(\mathrm{O}) 2$ & $(\mathrm{O}) 2$ & (I) 2 \\
\hline tRNA ${ }^{\mathrm{Ser}}-\mathrm{ND} 1$ & $(\mathrm{O}) 1$ & $(\mathrm{O}) 1$ & $(\mathrm{O}) 2$ & $(\mathrm{O}) 2$ & (I) 13 & $(\mathrm{O}) 2$ & (I) 6 & (I) 17 & (I) 13 & (I) 20 & (I) 17 \\
\hline ND1-tRNA ${ }^{\text {Leu }}$ & (I) 10 & (I) 1 & (I) 1 & (I) 3 & (I) 7 & - & (I) 1 & (I) 1 & (I) 1 & (I) 1 & (I) 1 \\
\hline tRNA ${ }^{\mathrm{Leu}}$-lrRNA & - & (I) 11 & - & - & - & - & - & - & - & - & - \\
\hline lrRNA-tRNA ${ }^{\text {Val }}$ & (I) 7 & (I) 7 & - & - & - & - & - & $(\mathrm{O}) 1$ & - & - & - \\
\hline tRNA $^{\mathrm{Val}}$-srRNA & (I) 1 & (I) 1 & - & - & - & - & - & - & - & - & - \\
\hline Total nucleotides & $\begin{array}{r}(\mathrm{I}) 306 \\
(\mathrm{O}) 133 \\
\end{array}$ & $\begin{array}{c}\text { (I) } 607 \\
\text { (O)106 } \\
\end{array}$ & $\begin{array}{l}\text { (I) } 129 \\
\text { (O)66 }\end{array}$ & $\begin{array}{l}\text { (I) } 97 \\
\text { (O) } 34\end{array}$ & $\begin{array}{l}\text { (I) } 155 \\
\text { (O) } 33 \\
\end{array}$ & $\begin{array}{l}(\mathrm{I}) 33 \\
(\mathrm{O}) 64 \\
\end{array}$ & $\begin{array}{l}(\mathrm{I}) 82 \\
(\mathrm{O}) 32 \\
\end{array}$ & $\begin{array}{l}\text { (I) } 146 \\
\text { (O)92 } \\
\end{array}$ & $\begin{array}{l}\text { (I) } 151 \\
\text { (O)29 } \\
\end{array}$ & $\begin{array}{l}\text { (I) } 116 \\
\text { (O)32 }\end{array}$ & $\begin{array}{l}\text { (I) } 96 \\
\text { (O) } 27 \\
\end{array}$ \\
\hline
\end{tabular}

The 22 tRNA are denoted by three-letter symbol. Species are indicated by the initial letter of its genus and the initial three letters of its specific name (see the corresponding full name in Tab. 2). (O) Overlapping sequences; (I) Intergenic spacer. Empty column means neighboring genes abutting each other.

exceptions. A previous study using transcript information from the cDNA sequence showed that the start codon for the COI gene was TCG (Serine) in dipteran insects (Krzywinski et al, 2006). In addition, TTAAAG has been previously proposed to be the start codon for the COI gene in Pieris rapae (Mao et al, 2010), ATTACG for Papilio xuthus (Feng et al, 2010), TTAG for Corean raphaelis (Kim et al, 2006), and TTG for Acraea issoria
(Hu et al, 2010) and Calinaga davidis (Xia et al, 2011).

In $A$. ilia, four genes ended with a single $\mathrm{T}$ right ahead of tRNA genes (Tab. 1). The single $\mathrm{T}$ residue could be completed into triplet codons by polyadenylation (Clary et al, 1985), and the tRNA secondary structure is functional to the precise cleavage of the mature protein-coding genes from the primary multicistronic transcripts (Ojala et al, 1980, 1981). 
The AT bias of the protein-coding genes in A. ilia was prominent with AT content of $78.9 \%$, the same as the average value of sequenced nymphalid mitogenomes (78.9\%) (Tab. 2). Additionally, the PCG nucleotide frequency was $\mathrm{T}>\mathrm{A}>\mathrm{G}>\mathrm{C}$, displaying significant skews at AT $(-0.15)$ and GC (0.02), both comparable to other sequenced lepidopterans (Liao et al, 2010). Examination of the concatenated 13 PCGs showed that the third codon position $(91.7 \%)$ contained higher AT content than the first (74.4\%) and second (70.9\%) positions, and this case is also similar to other sequenced lepidopteran species like Happrchia autonoe (Kim et al, 2010). As for $\mathrm{A}+\mathrm{T}$ content among 13 PCGs, ATP8 had the highest (93.9\%) and COI has the lowest (72.4\%) values (Tab. 2).

The $A$. ilia mitogenome also has an AT bias in codon usage. Among 3711 codons there were 451 UUAs, 439 AUUs, 344 UUUs, 270 AUAs, 229 AAUs and 164 UAUs. These codons have much higher frequencies than others (Tab. 5).

Tab. 5 Codon usage of PCGs in the Apatura ilia mitogenome

\begin{tabular}{|c|c|c|c|c|c|c|c|c|c|c|c|}
\hline Codon & Num. & RSCU & Codon & Num. & RSCU & Codon & Num. & $\mathrm{RSCU}$ & Codon & Num. & RSCU \\
\hline UUU(F) & 344 & 1.81 & UCU(S) & 106 & 2.58 & UAU(Y) & 164 & 1.76 & UGU(C) & 30 & 1.76 \\
\hline UUC(F) & 36 & 0.19 & $\mathrm{UCC}(\mathrm{S})$ & 9 & 0.22 & UAC(Y) & 22 & 0.24 & UGC(C) & 4 & 0.24 \\
\hline UUA(L) & 451 & 5.03 & UCA(S) & 100 & 2.43 & UAA(*) & 0 & 0.00 & UGA(W) & 89 & 1.89 \\
\hline UUG(L) & 25 & 0.28 & $\mathrm{UCG}(\mathrm{S})$ & 1 & 0.02 & $\mathrm{UAG}(*)$ & 0 & 0.00 & UGG(W) & 5 & 0.11 \\
\hline CUU(L) & 38 & 0.42 & $\mathrm{CCU}(\mathrm{P})$ & 62 & 2.10 & CAU(H) & 56 & 1.65 & CGU(R) & 16 & 1.21 \\
\hline CUC(L) & 4 & 0.04 & $\mathrm{CCC}(\mathrm{P})$ & 18 & 0.61 & $\mathrm{CAC}(\mathrm{H})$ & 12 & 0.35 & CGC(R) & 2 & 0.15 \\
\hline CUA(L) & 20 & 0.22 & $\mathrm{CCA}(\mathrm{P})$ & 36 & 1.22 & $\mathrm{CAA}(\mathrm{Q})$ & 53 & 1.83 & CGA(R) & 30 & 2.26 \\
\hline CUG(L) & 0 & 0.00 & $\mathrm{CCG}(\mathrm{P})$ & 2 & 0.07 & CAG(Q) & 5 & 0.17 & CGG(R) & 5 & 0.38 \\
\hline AUU(I) & 439 & 1.88 & $\operatorname{ACU}(\mathrm{T})$ & 77 & 2.07 & AAU(N) & 229 & 1.81 & AGU(S) & 35 & 0.85 \\
\hline $\mathrm{AUC}(\mathrm{I})$ & 27 & 0.12 & $\mathrm{ACC}(\mathrm{T})$ & 11 & 0.30 & $\mathrm{AAC}(\mathrm{N})$ & 24 & 0.19 & AGC(S) & 2 & 0.05 \\
\hline AUA(M) & 270 & 1.81 & $\mathrm{ACA}(\mathrm{T})$ & 61 & 1.64 & $\operatorname{AAA}(\mathrm{K})$ & 93 & 1.79 & AGA(S) & 75 & 1.82 \\
\hline AUG(M) & 29 & 0.19 & $\operatorname{ACG}(\mathrm{T})$ & 0 & 0.00 & $\mathrm{AAG}(\mathrm{K})$ & 11 & 0.21 & AGG(S) & 1 & 0.02 \\
\hline GUU(V) & 64 & 1.94 & GCU(A) & 67 & 2.37 & GAU(D) & 61 & 1.82 & GGU(G) & 53 & 1.08 \\
\hline GUC(V) & 1 & 0.03 & GCC(A) & 8 & 0.28 & GAC(D) & 6 & 0.18 & GGC(G) & 12 & 0.24 \\
\hline GUA(V) & 62 & 1.88 & GCA(A) & 37 & 1.31 & GAA(E) & 66 & 1.81 & GGA(G) & 102 & 2.07 \\
\hline GUG(V) & 5 & 0.15 & GCG(A) & 1 & 0.04 & GAG(E) & 7 & 0.19 & GGG(G) & 30 & 0.61 \\
\hline
\end{tabular}

A total of 3711 codons are analysed, excluding the termination codons. Num: number of each codon. RSCU: relative synonymous codon usage. *: stop codons.

\subsection{Transfer RNA genes and ribosomal RNA genes}

The DHU arm of tRNA ${ }^{\text {ser }}(\mathrm{AGN})$ has only a simple loop, common in most insects (Hong et al, 2008; Kim et al, 2006; Salvato et al, 2008; Wolstenholme, 1992). Similar to Parnassius bremeri (Kim et al, 2009), the tRNAs of $A$. ilia harbor 7 base pairs in amino-acyl stems, 5 base pairs in anticodon stems, and 7 base pairs in anticodon loop. However, the base pair numbers vary in

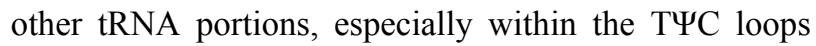
(3-10 bp) (Tab. 3).

Among the 22 tRNA genes 32 mismatched base pairs were found, 10 on the amino acyl stem, 9 on the DHU stem, 1 on the TYC stem and 9 on the anticodon stem. Twenty were between guanine and uracil, justifiable in terms of structural stableness (Topal \& Fresco, 1976). Some unconventional mismatches were also observed, e.g. A-C (1), A-G (1), and U-U (8). Similar cases were also seen in other lepidopteran species. For example, $C$. raphaelis has 8 U-U mismatches in tRNAs; $A$. issoria exhibits a G-A and a C$\mathrm{U}$ mismatches in the tRNA ${ }^{\mathrm{Ile}} ; H$. autonoe contains a U-U and a A-C mismatches in tRNA ${ }^{\text {Leu }}$ (UUR), H. cunea has $\mathrm{U}-\mathrm{U}$ mismatches in tRNA ${ }^{\mathrm{Ala}}$, tRNA ${ }^{\mathrm{Leu}}(\mathrm{CUN})$, and tRNA $^{\text {Leu }}$ (UUR) (Liao et al, 2010). These mismatches can be corrected through RNA-editing mechanisms that are well known for arthropod mtDNA (Lavrov et al, 2000)

As in other lepidopteran species, the A. ilia mitogenome was found to harbor two rRNA genes (776 bp srRNA and 1333 bp lrRNA). The AT content of srRNA was $84.9 \%$, similar to those of other lepidopteran insects $(87.5 \%$ for Phthonandria atrilineata (Yang et al, 2009), 82.0\% for Ostrinia furnacalis (Coates et al, 2005)) (Tab.2). The AT content of lrRNA (85.0\%) also fell into the range for other lepidopteran insects $(85.1 \%$ for $P$. atrilineata, $81.4 \%$ for Ostrinia Lunifer (Salvato et al, 2008)) (Tab. 2). 


\subsection{Intergenic spacer and overlapping sequence}

The spacer 1 of 49 bp was located between the tRNA $^{\text {Gln }}$ and ND2 genes and this spacer had the same size to that in $O$. furnicalis, Ostrinia nubilalis (Coates et al, 2005), B. mori and B. mandarina (Yukuhiro et al, 2002). It has been suggested that the spacer would remain invariant in length in some congeneric species (Cameron \& Whiting, 2008), however, new findings showed divergence among Apatura Metis (unpublished, NC-015537) and A. ilia (Tab. 4). The comparison of this spacer with the neighboring ND2 gene showed 63\% homology. Likewise, the cases for $H$. autonoe (74\%), $P$. bremeri (70\%), P. atrilineata $(70 \%)$, C. raphaelis $(62 \%)$, A. melete (70\%) and B. mori (63\%) all suggest that this spacer sequence originated from the ND2 gene (Kim et al, 2009).

Like spacer 1, spacer 2 was also 49 bp in length and found between ND6 and Cyt b. It is notable that a microsatellite-like repeat (TA) $)_{23}$ was identified within this region. This case is extremely rare among the known nymphalid mitogenomes (the other example is in $A$. metis which has (TA) $)_{12}$ in this region).

Spacer 3 was 13 bp and located between tRNA ${ }^{\text {Ser }}$ (CUN) and ND1. This spacer sequence held a 7-base motif ATACTAA. A similar motif has been identified in previous studies as a plausible conservancy in all Lepidoptera species sequenced so far (Kim et al, 2009; Cameron \& Whiting, 2008; Liao et al, 2010; Salvato et al, 2008). It may be functionally essential in the recognition of the mtDNA TERM (the transcription termination peptide). Recent mitogenomic sequence data has demonstrated mixed results in Nymphalidae species. For example, in H. autonoe a 6-bp spacer (Kim et al, 2010) was located between tRNA ${ }^{\text {Ser }}$ (CUN) and ND1, and the 7-bp motif ATACTAA located within tRNA ${ }^{\text {Ser }}$ (CUN), whereas in $C$. dauidis, A. hyperbius and A. issoris, the two genes were overlapped for 1 or $2 \mathrm{bp}$ and the motif was located at the 3' end of the ND1 gene.

The 12-bp spacer 4 was located between ND4L and tRNA $^{\text {Thr }}$, being longer than those of other nymphalid species. All remaining spacers in A. ilia are less than 10 bp.

We also found two overlapping sequences which are conservative in Lepidoptera, one was $7 \mathrm{bp}$ long and the other $8 \mathrm{bp}$. The 7-bp sequence was located between ATP8 and ATP6 as ATGATAA, and the 8-bp overlap was located between tRNA $^{\text {Trp }}$ and $\operatorname{tRNA}^{\text {Cys as }}$
AAGCCTTA, These two sequences have also been detected in other lepidopteran insects, such as P. bremeri, $H$. cunea and $P$. atrilineata. Based on data of the presently sequenced lepidopteran insects, the two overlapping sequences were postulated to be conservative across lepidopteran insect taxa. Another 5bp sequence was located between COI and tRNA ${ }^{\text {Leu }}$. The remaining five overlapping sequences range from 1 to 3 in size. So far the 3-bp overlap between tRNA ${ }^{\text {Ile }}$ and tRNA $^{\text {Gln }}$ has been found in all sequenced Nymphalidae species.

\subsection{A+T-rich region}

The AT-rich region functional in mtDNA replication and transcription (Taanman, 1999). The origin of the major-strand replication was studied in the AT-rich region in vertebrates (Tapper \& Clayton, 1981), followed by the detection on both strands of mtDNA in Drosophila species (Clary \& Wolstenholme, 1987; Fauron \& Wolstenholmn, 1980). In recent years investigations were expended to the replication origin of the minor-strand in Diptera, Lepidoptera, Coleoptera and Orthoptera, and the results suggest that the replication origin site of mtDNA minor-strand in insects is located before the poly-T structure, which is standing at the 3' end of the AT-rich region (Saito et al, 2005).

The AT-rich region of $A$. ilia has some common or similar structural features for lepidopteran insects. It harbors a 21-bp poly-T stretch located 18 bp upstream from srRNA and preceded by a motif ATAGA. The poly-T stretch and the motif composed the origin site for the minor-strand replication, recognizable as a structural signal by regulating proteins (Kim et al, 2009). Additionally, there are two microsatellite-like repeats of $(\mathrm{TA})_{10}$ and $(\mathrm{TA})_{7}$, which are preceded by a conserved motif ATTTA and located upstream of $(\text { TA })_{10}$ repeat. At the 5' end of this region there is a 14-bp poly-A structure, shortened to be $10 \mathrm{bp}$ by inserting a single $\mathrm{T}$ base. A similar case was found for other nymphalid butterfly species; for example, the poly-A of $A$. issoris mtDNA was inserted by a guanine. Functionally, the poly-A was assumed to be the replication origin location of the mtDNA major-strand because of its connection with tRNA $^{\text {Met }}$ (Kim et al, 2009).

Acknowledgements: We thank ZHU Shun-Yi (College of Life Sciences, Shanxi University, China) for critical comments on an earlier version of this paper. 


\section{References:}

Avise JC. 1994. Molecular Markers, Natural History and Evolution[M]. New York: Champman \& Hall.

Boore JL. 1999. Animal mitochondrial genomes[J]. Nucleic Acids Res, 27(8): 1767-1780.

Boore JL, Lavrov DV, Brown WM. 1998. Gene translocation links insects and crustaceans[J]. Nature, 392(6677): 667-668.

Brown WM. 1983. Evolution of animal mitochondrial DNA[M] // Nei M, Koehn RK. Evolution of Genes and Proteins. Sunderland, MA: Sinauer.

Cameron SL, Whiting MF. 2008. The complete mitochondrial genome of the tobacco hornworm, Manduca sexta, (Insecta: Lepidoptera: Sphingidae), and an examination of mitochondrial gene variability within butterflies and moths[J]. Gene, 408(1-2): 112-123.

Chou I. 1998. Classification and Identification of Chinese Butterflies[M]. Zhengzhou: Henan Scientific and Technological Publishing House.

Chou I. 2000. Monographia Rhopalocerorum Sinensium[M]. Zhengzhou: Henan Scientific and Technological Publishing House.

Clary DO, Wolstenholme DR. 1985. The mitochondrial DNA molecule of Drosophila yakuba: nucleotide sequence, gene organization, and genetic code[J]. J Mol Evol, 22(3): 252-271.

Clary DO, Wolstenholme DR. 1987. Drosophila mitochondrial DNA: Conserved sequences in the $\mathrm{A}+\mathrm{T}$-rich region and supporting evidence for a secondary structure model of the small ribosomal RNA[J]. J Mol Evol, 25(2): 116-125.

Clayton DA. 1992. Transcription and replication of animal mitochondrial DNAs[J]. Int Rev Cytol, 141: 217-232.

Coates BS, Sumerford DV, Hellmich RL, Lewis LC. 2005. Partial mitochondrial genome sequences of Ostrinia nubilalis and Ostrinia furnicalis[J]. Int J Biol Sci, 1(1): 13-18.

Crozier RH, Crozier YC. 1993. The mitochondrial genome of the honeybee Apis mellifera: complete sequence and genome organization[J]. Genetics, 133(1): 97-117.

Dotson EM, Beard CB. 2001. Sequence and organization of the mitochondrial genome of the Chagas disease vector, Triatoma dimidiata[J]. Insect Mol Biol, 10(3): 205-215.

Fauron CMR, Wolstenholmn DR. 1980. Extensive diversity among Drosophila species with respect to nucleotide sequences within the adenine + thymine-rich region of mitochondrial DNA molecules[J]. Nucleic Acids Res, 8(11): 2439-2452.

Feng X, Liu DF, Wang NX, Zhu CD, Jiang GF. 2010. The mitochondrial genome of the butterfly Papilio xuthus (Lepidoptera: Papilionidae) and related phylogenetic analyses[J]. Mol Biol Rep, 37(8): 3877-3888

Hao JS, Li CX, Sun XY, Yang Q. 2005. Phylogeny and divergence time estimation of Cheilostome bryozoans based on mitochodrial 16S rRNA sequences[J]. Chn Sci Bull, 50(12): 1205-1211.

Hong MY, Lee EM, Jo YH, Park HC, Kim SR, Hwang JS, Jin BR, Kang PD, Kim KG, Han YS, Kim I. 2008. Complete nucleotide sequence and organization of the mitogenome of the silk moth Caligula boisduvalii (Lepidoptera: Saturniidae) and comparison with other lepidopteran insects[J]. Gene, 413(1-2): 49-57.

Hu J, Zhang DX, Hao JS, Huang DY, Cameron S, Zhu CD. 2010. The complete mitochondrial genome of the yellow coaster, Acraea issoria (Lepidoptera: Nymphalidae: Heliconiinae: Acraeini): sequence, gene organization and a unique tRNA translocation event[J]. Mol Biol Rep, 37(7): 3431-3438.

Jiang ST, Hong GY, Yu M, Li N, Yang Y, Liu YQ, Wei ZJ. 2009.
Characterization of the complete mitochondrial genome of the giant silkworm moth, Eriogyna pyretorum (Lepidoptera: Saturniidae)[J]. Int Biol Sci, 5(4): 351-365.

Kim I, Lee EM, Seol KY, Yun EY, Lee YB, Hwang JS, Jin BR. 2006. The mitochondrial genome of the Korean hairstreak, Coreana raphaelis (Lepidoptera: Lycaenidae)[J]. Insect Mol Biol, 15(2): 217-225.

Kim MI, Baek JY, Kim MJ, Jeong HC, Kim KG, Bae CH, Han YS, Jin BR, Kim I. 2009. Complete nucleotide sequence and organization of the mitogenome of the red-spotted Apollo butterfly, Parnassius bremeri (Lepidoptera: Papilionidae) and comparison with other lepidopteran insects[J]. Mol Cells, 28(4): 347-363.

Kim MJ, Wan XL, Kim KG, Hwang JS, Kim I. 2010. Complete nucleotide sequence and organization of the mitogenome of endangered Eumenis autonoe (Lepidoptera: Nymphalidae)[J]. Afr J Biotechnol, 9(5): 735-754.

Krzywinski J, Grushko OG, Besansky NJ. 2006. Analysis of the complete mitochondrial DNA from Anopheles funestus: An improved dipteran mitochondrial genome annotation and a temporal dimension of mosquito evolution[J]. Mol Phylogenet Evol, 39(2): 417-423.

Lavrov DV, Brown WM, Boore JL. 2000. A novel type of RNA editing occurs in the mitochondrial tRNAs of the centipede Lithobius forficatus[J]. Proc Natl Acad Sci USA, 97(25): 13738-13742.

Lee ES, Shin KS, Kim MS, Park H, Cho S, Kim CB. 2006. The mitochondrial genome of the smaller tea tortrix Adoxophyes honmai (Lepidoptera: Tortricidae)[J]. Gene, 373: 52-57.

Lessinger AC, Martins Junqueira AC, Lemos TA, Kemper EL, Da Silva FR, Vettore AL, Arruda P, Azeredo-Espin AML. 2000. The mitochondrial genome of the primary screwworm fly Cochliomyia hominivorax (Diptera: Calliphoridae)[J]. Insect Mol Biol, 9(5): 521-529.

Liao F, Wang L, Wu S, Li YP, Zhao L, Huang MG, Niu CJ, Liu YQ, Li MG. 2010. The complete mitochondrial genome of the fall webworm, Hyphantria cunea (Lepidoptera: Arctiidae)[J]. Int Biol Sci, 6(2): 172-186.

Li ZW, Fu YL. 2000. Endangered and protected butterflies in the world[J]. J Hainan Norm Univ Nat Sci, 5(2): 102-107.

Lowe TM, Eddy SR. 1997. tRNAscan-SE: a program for improved detection of transfer RNA genes in genomic sequence[J]. Nucleic Acids Res, 25(5): 955-964.

Mao ZH, Hao JS, Zhu GP, Hu J, Si MM, Zhu CD. 2010. Sequencing and analysis of the complete mitochondrial genome of Pieris rapae Linnaeus (Lepidoptera: Pieridae)[J]. Acta Entomol Sin, 53(11): 1295-1304.

Mathews DH. 2006. RNA secondary structure analysis using RNA structure[J]. Curr Protocol Bioinform, 12(6): 1-14.

Ojala D, Merkel C, Gelfand R, Attardi G. 1980. The tRNA genes punctuate the reading of genetic information in human mitochondrial DNA[J]. Cell, 22(2): 393-403.

Ojala D, Montoya J, Attardi G. 1981. tRNA punctuation model of RNA processing in human mitochondria[J]. Nature, 290(5806): 470-474.

Robbins RK. 1982. How many butterfly species[J]. News Lepid Soc, 1982: 41-42.

Saito S, Tamuea K, Aotsuka T. 2005. Replication origin of mitochondrial DNA in insects[J]. Genetics, 171(4): 1695-1705.

Salvato P, Simonato M, Battist A, Negrisolo E. 2008. The complete mitochondrial genome of the bag-shelter moth Ochrogaster lunifer 
(Lepidoptera: Notodontidae)[J]. BMS Genomics, 9(1): 331.

Simon C, Frati F, Bekenbach A, Crespi B, Liu H, Flook P. 1994. Evolution, weighting, and phylogenetic utility of mitochondrial gene sequences and a compilation of conserved polymerase chain reaction primers[J]. Ann Entomol Soc Am, 87(6): 651-701.

Simons RB, Weller SJ. 2001. Utility and evolution of cytochrome b in insects[J]. Mol Phylogenet Evol, 20(2): 196-210.

Singh VK, Mangalam AK, Dwivedi S, Naik S. 1998. Primer premier: Program for design of degenerate primers from a protein sequence[J]. Biotechnique, 24(2): 318-319.

Taanman JW. 1999. The mitochondrial genome: structure, transcription, translation and replication[J]. Biochim Biophys Acta, 1410(2): 103-123.

Tamura K, Dudley J, Nei M, Kumar S. 2007. MEGA 4 : molecular evolutionary genetics analysis (MEGA) software version 4.0[J]. Mol Biol Evol, 24(8): 1596-1599.

Tapper DA, Clayton DA. 1981. Mechanism of replication of human mitochondrial DNA: localization of the 5' ends of nascent daughter strands[J]. J Biol Chem, 256(10): 5109-5115.

Thompson JD, Gibson TJ, Plewniak F, Jeanmougin F, Higgins DG. 1997. The clustal $\mathrm{X}$ windows interface: flexible strategies for multiple sequence alignment aided by quality analysis tools[J]. Nucleic Acids Res, 25(24): 4876-4882.

Topal MD, Fresco JR. 1976. Complementary base pairing and the origin of substitution mutations[J]. Nature, 263(5575): 285-289.
Wang XC, Sun XY, Sun QQ, Zhang DX, Hu J, Yang Q, Hao JS. 2011. The complete mitochondrial genome of the laced fritillary Argyreus hyperbius (Lepidoptera: Nymphalidae)[J]. Zool Res, 32(5): 465-475.

Wolstenholme DR. 1992. Animal mitochondrial DNA: structure and evolution[J]. Int Rev Cytol, 141: 173-216.

Wu LW, Lees DC, Yen SH, Lu CC, Hsu YF. 2010. The complete mitochondrial genome of the near-threatened swallowtail, Agehana maraho (Lepidoptera: Papilionidae): evaluating sequence variability and suitable markers for conservation genetic studies[J]. Etomol News, 121(3): 267-280.

Xia J, Hu J, Zhu GP, Zhu CD, Hao JS. 2011. Sequencing and analysis of the complete mitochondrial genome of Calinaga davidis Oberthür (Lepidoptera: Nymphalidae)[J]. Acta Entomol Sin, 54(5): 555-565.

Yang L, Wei ZJ, Hong JY, Jang ST, Wen LP. 2009. The complete nucleotide sequence of the mitochondrial genome of Phthonandria atrilineata (Lepidoptera: Geometridae)[J]. Mol Biol Rep, 36(6): 1441-1449.

Yukuhiro K, Sezutsu H, Itoh M, Schmizu K, Banno Y. 2002. Significant levels of sequence divergence and gene rearrangements have occurred between the mitochondrial genomes of the wild mulberry silkmoth, Bombyx mandarina, and its close relative, the domesticated silkmoth, Bombyx mori[J]. Mol Biol Evol, 19(8): 1385-1389.

\section{地图勘误说明}

地图事关国家安全、主权、民族尊严和中华民族的根本利益，历来受到国家的高度重视。依据《中 华人民共和国地图编制出版管理条例》和《地图审核管理规定》的有关要求，中国地图全图中不得缺少 香港特别行政区、澳门特别行政区、海南岛、台湾岛、钓鱼岛、南海诸岛、赤尾屿及海域国界线等。本 刊 2011 年 32 卷第 181、569 和 578 页相应示意图的中国地图全图中缺少南海诸岛、钓鱼岛、赤尾屿及海 域国界线等，特此勘误说明。希望此勘误能够引起作者和编者的足够重视。 


\section{《猴、猿、人一一思考人性的起源》新书简介}

中山大学人类学系的张鹏著《猴、猿、人一思考人性的起源》一书已于 2012 年 1 月由中山大学出版 社出版。书中全面讨论了人与猿猴的异同, 尝试从灵长类进化的新视角探索人性起源, 解释人类的共通 性及其生物学本质, 并为读者提供理解自身的新思维。目前国内灵长类的书籍不多, 欢迎读者订阅!

《猴、猿、人一一思考人性的起源》简介:

毫无疑问，人类是 600 余种灵长类中的一种。解剖学者说猿猴的手掌、指纹、大脑等身体结构与人 类似。行为生态学者说猿猴的行为和复杂社会关系与人类似。人类学者说猿猴的工具使用技能和文化传 播可能接近于人类的维形阶段。心理学者说猿猴是地球上最聪明的动物。保护生物学学者说有猿猴生活 的森林一定是最健康的森林, 保护猿猴就是保护森林生态。医学工作者说猿猴的免疫系统接近于人, 是 克服人类疾病的最佳模型动物。分子生物学者说黑猩猩属与人类基因相似度高达 $98.7 \%$, 是与人类最近 缘的物种。可以说，猿猴是一面多棱镜，从方方面面映射出人性起源的背景。

本书是目前国内第一本综合介绍灵长类知识的书籍。书中全面讨论了人与猿猴的异同, 尝试从灵长 类进化的新视角探索人性起源, 解释人类的共通性及其生物学本质, 并为读者提供理解自身的新思维。 第一章介绍了人类的生物属性, 第二章进一步详细介绍了近代灵长类学的诞生与发展过程; 从第三章到 第十章, 分章节介绍了灵长类的起源与分类、生态、行为、社会、文化、智能、疾病与遗传、生命伦理 与保护等各方面知识。第十一章总结了人类与猿猴的区别, 以及解答如何界定人类等长期未解的自身谜 团。

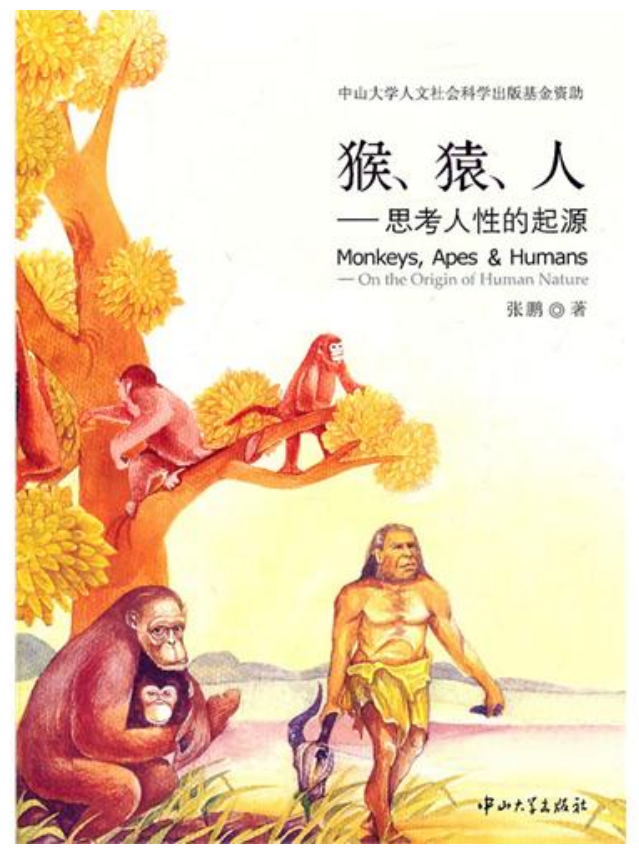

《猴、猿、人一一思考人性的起源》章节目录:

序一 (日本京都大学渡边邦夫)
序二 (中山大学麻国庆)
前言
第一章 人类的生物属性
第二章 灵长类学的诞生与发展
第三章 灵长类的起源与分类
第四章 灵长类的生态
第五章 灵长类的行为
第六章 灵长类的社会
第七章 灵长类的文化
第八章 灵长类的智能
第九章 灵长类的疾病与遗传
第十章 灵长类的生命与保护
第十一章 结语: 人性的起源
参考文献
附录

欲购买请联系中山大学出版社（电话 020-84111995) 或网上购书, 当当网 http: //product. dangdang. com/product. aspx?product_id=22603988\#content。

友情链接: 张鹏和渡边邦夫著 《灵长类的社会进化》, 2009 年, 中山大学出版社; 可从网上购 买, 当当网 $h t t p:$ / product. dangdang. com/product. as px? product $t_{-} i d=20727953$ 。 